\title{
Papers
}

\section{Efficacy and safety of galantamine in patients with mild to moderate Alzheimer's disease: multicentre randomised controlled trial}

\author{
Gordon K Wilcock, Sean Lilienfeld, Els Gaens on behalf of the Galantamine International-1 \\ Study Group
}

\begin{abstract}
Objective To evaluate the efficacy and safety of galantamine in the treatment of Alzheimer's disease. Design Randomised, double blind, parallel group, placebo controlled trial.

Setting 86 outpatient clinics in Europe and Canada. Participants 653 patients with mild to moderate Alzheimer's disease.

Intervention Patients randomly assigned to galantamine had their daily dose escalated over three to four weeks to maintenance doses of 24 or $32 \mathrm{mg}$.

Main outcome measures Scores on the 11 item cognitive subscale of the Alzheimer's disease assessment scale, the clinician's interview based impression of change plus caregiver input, and the disability assessment for dementia scale. The effect of apolipoprotein $\mathrm{E} 4$ genotype on reponse to treatment was also assessed.

Results At six months, patients who received galantamine had a significantly better outcome on the 11 item cognitive subscale of the Alzheimer's disease assessment scale than patients in the placebo group (mean treatment effect 2.9 points for lower dose and 3.1 for higher dose, intention to treat analysis, $\mathrm{P}<0.001$ for both doses). Galantamine was more effective than placebo on the clinician's interview based impression of change plus caregiver input $(\mathrm{P}<0.05$ for both doses $v$ placebo). At six months, patients in the higher dose galantamine group had significantly better scores on the disability assessment for dementia scale than patients in the placebo group (mean treatment effect 3.4 points, $\mathrm{P}<0.05$ ).

Apolipoprotein E genotype had no effect on the efficacy of galantamine. 80\% (525) of patients completed the study.

Conclusion Galantamine is effective and well tolerated in Alzheimer's disease. As galantamine slowed the decline of functional ability as well as cognition, its effects are likely to be clinically relevant.
\end{abstract}

\section{Introduction}

Cholinergic deficits are the most prominent neurochemical disturbances in patients with Alzheimer's disease and are thought to contribute to the deterioration in memory and other cognitive functions. ${ }^{1}$ Several pharmacological approaches have been used in an attempt to correct these deficits, including increasing the synthesis of acetylcholine, activation of muscarinic or nicotinic acetylcholine receptors, and inhibition of acetylcholinesterase, the enzyme responsible for the hydrolysis of acetylcholine. ${ }^{2}$ Of these strategies, inhibition of acetylcholinesterase is currently the most successful treatment for Alzheimer's disease. ${ }^{3}$ Well designed clinical trials have consistently shown improved cognition and global assessment scores in patients taking acetylcholinesterase inhibitors. ${ }^{34}$ The effects of cholinesterase inhibitors on patients' activities of daily living are unclear. ${ }^{56}$ There is also some evidence that patients who have the apolipoprotein $\mathrm{E} 4$ genotype may have a reduced response to cholinesterase inhibitors. ${ }^{78}$

Galantamine is a new drug that reversibly and competitively inhibits acetylcholinesterase ${ }^{910}$ and enhances the response of nicotinic receptors to acetylcholine. ${ }^{11}$ This enhancement of nicotinic neurotransmission may be clinically relevant because activation of presynaptic nicotinic receptors increases the release of acetylcholine and other neurotransmitters, such as glutamate, that are deficient in patients with Alzheimer's disease. ${ }^{12} 13$

We evaluated the efficacy and safety of two maintenance doses of galantamine over six months compared with placebo in patients with mild to moderate Alzheimer's disease. We also investigated whether the apolipoprotein $\mathrm{E} 4$ genotype influences the response to galantamine.

\section{Participants and methods}

We studied outpatients who had a history of cognitive decline that had been gradual in onset and progressive over at least six months. Participants had to meet the criteria for probable Alzheimer's disease set out by the National Institute of Neurological and Communicative Disorders and Stroke and the Alzheimer's Disease and Related Disorders Association ${ }^{14}$ and to have mild to moderate dementia, defined as a score of 11-24 on the mini-mental state examination ${ }^{15}$ and a score of $\geqslant 12$ on the 11 item cognitive subscale of the Alzheimer's

\author{
Department of Care \\ of the Elderly, \\ Frenchay Hospital, \\ University of \\ Bristol, Bristol \\ BS16 1LE \\ Gordon K Wilcock \\ professor in care of the \\ elderly \\ Central Nervous \\ System Clinical \\ Research, Janssen \\ Research \\ Foundation, Beerse, \\ Belgium \\ Sean Lilienfeld \\ director \\ Els Gaens \\ statistician \\ Correspondence to: \\ G K Wilcock \\ Gordon.Wilcock@ \\ bris.ac.uk \\ Clinical \\ investigators in the \\ Galantamine \\ International-1 \\ Study Group are \\ listed at the end of \\ the paper.
}

BMJ 2000;321:1-7 
disease assessment scale. ${ }^{16}$ Patients had to live with, or be visited at least five days a week by, a responsible caregiver. The caregiver together with the patient (or their relative, guardian, or legal representative) provided written informed consent to participate in the study. Patients with concomitant diseases such as hypertension, heart failure (New York Heart Association grade I-II), type 2 diabetes mellitus, and hypothyroidism were included in the study provided that their illness was controlled.

Patients were excluded from the study if they had any other neurodegenerative disorder; multi-infarct dementia or clinically active cerebrovascular disease; cardiovascular disease thought likely to prevent completion of the study; clinically important cerebrovascular, psychiatric, hepatic, renal, pulmonary, metabolic, or endocrine conditions or urinary outflow obstruction; an active peptic ulcer; or any history of epilepsy or serious drug or alcohol misuse. We also excluded patients who had been treated for Alzheimer's disease with a cholinesterase inhibitor. Any other drugs being taken to treat dementia had to be discontinued before participation in the study. The use of drugs for other conditions was permitted during the study, except that sedative-hypnotic drugs and sedating cough and cold remedies were discontinued, if possible, in the 48 hours before cognitive evaluation. Any other drugs with anticholinergic or cholinomimetic effects were avoided if possible. A blood sample was taken at baseline for apolipoprotein E genotyping. ${ }^{17}$ The trial was performed in accordance with the Declaration of Helsinki and its subsequent revisions and approved by ethics committees at each centre.

\section{Design}

This was a six month, parallel group, double blind, placebo controlled trial undertaken in 86 centres in eight countries (Canada, Finland, France, Germany, Norway, Sweden, the Netherlands, and the United Kingdom). After a four week, single blind, placebo run-in phase, patients were randomly assigned to one of two galantamine treatment groups or a placebo group by simple randomisation. The randomisation schedule was computer generated at the Janssen Research Foundation. The assignments were kept in sealed, opaque, numbered envelopes, each containing the allocation for the next patient. Treatment was started on the day of allocation. The randomisation code was not broken until the database had been formally closed. In both galantamine groups, the galantamine regimen was $8 \mathrm{mg}$ daily for one week, increasing to 16 $\mathrm{mg}$ daily for the second week and to $24 \mathrm{mg}$ daily for the third week. In the fourth week, one galantamine group continued on $24 \mathrm{mg}$ while the other group had the dose increased to $32 \mathrm{mg}$ daily. Patients then continued with their target dose of galantamine or placebo for a further five months, during which time patients were reviewed monthly. To help maintain blinding, all individual doses of galantamine and placebo were taken twice daily and were identical in appearance, taste, and smell.

The primary efficacy variables used in the trial were the standard 11 item cognitive subscale of the Alzheimer's disease assessment scale (score range 0-70; higher scores indicate greater cognitive impairment $)^{16}$ to assess cognitive function (memory, attention, language, orientation, etc) and the clinician's interview based impression of change plus caregiver input, ${ }^{18}$ which provides a global impression of a patient's improvement or deterioration over the course of the illness. The clinician's interview was scored relative to baseline by a clinician blinded to other assessments and was based on separate interviews with the patient and the caregiver $(1=$ much improved, $4=$ no change, $7=$ much worse). The primary end point was at six months.

Secondary efficacy variables were the expanded (13 item) version of the standard 11 item cognitive subscale of the Alzheimer's disease assessment scale, the additional items being concentration or distractibility and delayed word recall (score range $0-85)^{19}$; the proportions of patients with improvements from baseline on the 11 item cognitive subscale of the Alzheimer's disease assessment scale of $\geqslant 0$ and $\geqslant 4$ points, based in part on US Food and Drug Administration's guidance on what is considered to be a clinically important effect $^{20}$; and the disability assessment for dementia scale, based on an interview with the caregiver, to assess activities of daily living (self care activities, instrumental (complex) activities of daily living, planning and organisation, leisure, effective performance, initiation). The disability assessment scale uses 46 questions and has a score range of 0-100 (higher scores indicate better functioning). ${ }^{21}$ These assessments were performed at baseline and after three and six months; the Alzheimer's disease assessment scale was also measured after three weeks. All efficacy variables were analysed as a change from baseline. If one item was missing from an assessment, that particular assessment was not included in the efficacy analysis.

Safety evaluations throughout the study comprised physical examinations, electrocardiography, measurements of vital signs, standard laboratory tests, and monitoring for adverse events (classified according to World Health Organization preferred terms). For the first month, the investigator contacted the patient or caregiver, or both, at weekly intervals to record any adverse events; thereafter, safety was evaluated at monthly clinic visits.

\section{Statistical analysis}

Based on data from a phase II trial (Janssen Research Foundation, unpublished data) we calculated that we needed about 180 patients in each treatment group to achieve $80 \%$ power $(\alpha=0.025$ with a Bonferroni adjustment) for detecting a 2.75 point difference in the change in 11 item cognitive subscale of the Alzheimer's disease assessment scores after six months between patients who received galantamine and those who received placebo. The 2.75 point change was considered to be clinically meaningful in view of the expected six month deterioration in patients in the placebo group and the magnitude of treatment difference in a trial of the cholinesterase inhibitor tacrine. ${ }^{22}$

All randomised patients who took at least one dose of trial drug were included in the analyses of baseline characteristics and safety data. The primary analysis for efficacy data was based on randomised patients who also provided any cognitive data at other designated assessment times - traditional "observed case" analysis. To confirm the robustness of the observed case analy- 
sis, we performed a six month intention to treat analysis that included all randomised patients who had any efficacy assessment, whether at baseline or during treatment. In this analysis, the last available assessment was carried forward into all subsequent assessment times for which actual data were not available. All results discussed are based on the observed case analysis unless otherwise stated.

Changes from baseline in efficacy variables, vital signs, electrocardiographic results, and body weight were assessed with the two sided, paired $t$ test. We used the following methods to compare variables between each galantamine group and the placebo group: analysis of variance, using treatment and country as factors, with pairwise Dunnett's tests for changes from baseline in cognitive subscales of the Alzheimer's disease assessment scale and the disability assessment for dementia; generalised Cochran-Mantel-Haenszel test, controlling for country, for response rates to the 11 item cognitive subscale of the Alzheimer's disease assessment scale; Van Elteren test, ${ }^{23}$ controlling for country, for the clinician's interview based impression of change plus caregiver input. The Van Elteren test is derived from the Cochran-Mantel-Haenszel test and uses modified ridit scores to assess differences in the distribution of scores between both galantamine groups and placebo. We used an analysis of variance, using treatment and country as factors, with pairwise Fisher's least significant difference tests, for changes from baseline in vital signs, electrocardiograms, and body weight. The time-response relation for change in the 11 item cognitive subscale of the Alzheimer's disease assessment scale was analysed by generalised linear mixed modelling. Exploratory analysis of variance was used to investigate any relation between baseline characteristics and changes in the 11 item cognitive subscale of the Alzheimer's disease assessment scale. All tests were evaluated at the $5 \%$ significance level. The statistical software used was SAS version 6.12.

\section{Results}

Of the 753 patients screened for the study, 653 were randomised to treatment. All randomised patients received at least one dose of trial medication. Of the 653 randomised patients, $87 \%(186 / 215)$ of those in the placebo group compared with $80 \%(176 / 220)$ and $75 \%(163 / 218)$ in the lower and higher galantamine dose groups, respectively, completed the study (fig 1). The baseline characteristics of the three treatment groups were comparable (table 1). Overall, 85\% (556/653) of patients received concomitant drugs during the double blind phase of the study, most commonly analgesics. The proportions of patients taking concomitant psychotropic drugs during the double blind phase were similar across groups (38\% (81) in placebo compared with $37 \%(81)$ and $41 \%(90)$ in the galantamine groups). The baseline characteristics of patients who completed the study remained comparable across the three treatment groups. Patients who did and did not complete the study had comparable baseline characteristics, except that those who did not complete were slightly older (mean age $74.1 v 71.7$ years).

Since serious protocol deviations occurred for only $28(4 \%)$ randomised patients, of which 18 were cases of non-compliance, we did not do per protocol analyses.

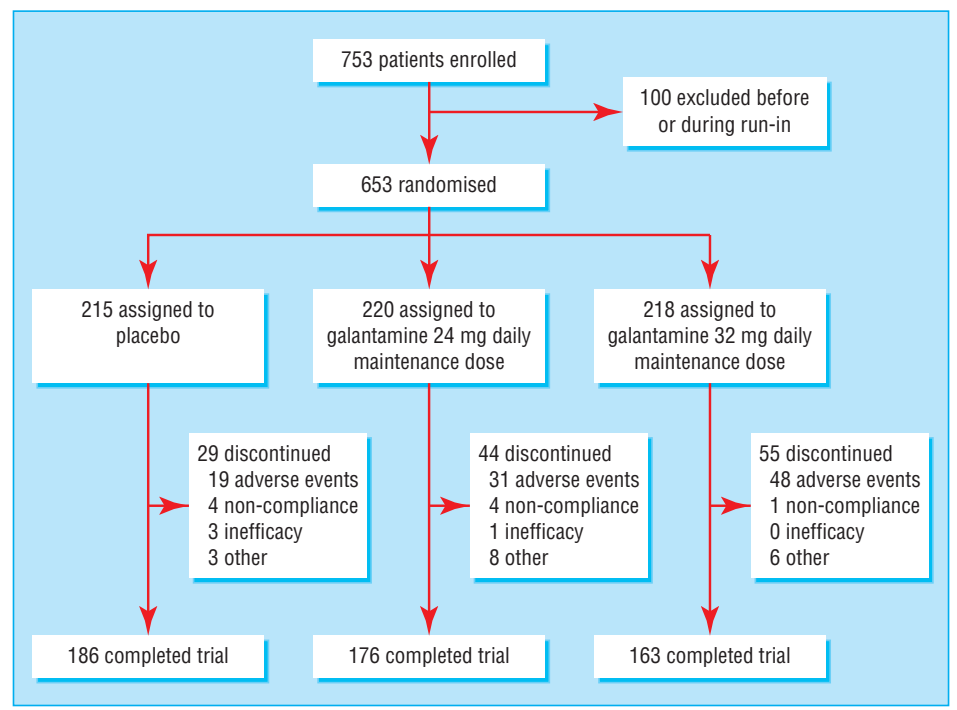

Fig 1 Profile of trial

Table 1 Baseline characteristics of participants. Values are numbers (percentages) unless stated otherwise

\begin{tabular}{|c|c|c|c|}
\hline Characteristic & $\begin{array}{l}\text { Placebo } \\
(\mathrm{n}=215)\end{array}$ & $\begin{array}{l}\text { Galantamine } \\
24 \mathrm{mg}(\mathrm{n}=220)\end{array}$ & $\begin{array}{c}\text { Galantamine } \\
32 \mathrm{mg}(\mathrm{n}=218)\end{array}$ \\
\hline \multicolumn{4}{|l|}{ Demography } \\
\hline Men/women & $83 / 132$ & $81 / 139$ & $80 / 138$ \\
\hline Mean (SD) age (years) & $72.7(7.6)$ & $71.9(8.3)$ & $72.1(8.6)$ \\
\hline \multicolumn{4}{|l|}{ Clinical } \\
\hline Mean (SD) weight $(\mathrm{kg})$ & $67.2(12.1)$ & $66.7(12.8)$ & $66.2(13.4)$ \\
\hline No $(\%)$ of smokers & $193(90)$ & $200(91)$ & $199(91)$ \\
\hline Other active medical conditions & $154(72)$ & $159(72)$ & $168(77)$ \\
\hline \multicolumn{4}{|l|}{ No (\%) with apolipoprotein E4 allele* } \\
\hline Homozygous & $34(18)$ & $32(17)$ & $27(15)$ \\
\hline Heterozygous & $83(45)$ & $97(53)$ & $95(53)$ \\
\hline Mean (SD) mini-mental state examination score & $19.3(3.5)$ & $19.5(3.4)$ & $19.0(3.8)$ \\
\hline Mean (SD) Alzheimer's disease assessment scale score $†$ & $24.7(9.3)$ & $25.4(9.4)$ & $26.2(10.4)$ \\
\hline Mean (SD) disability assessment in dementia score & $66.6(22.5)$ & $69.9(21.4)$ & $69.6(20.6)$ \\
\hline $\begin{array}{l}\text { Mean (SD) time since cognitive problem diagnosed } \\
\text { (years) }\end{array}$ & $3.5(2.3)$ & $3.6(2.7)$ & $3.7(2.2)$ \\
\hline $\begin{array}{l}\text { Mean (SD) time since probable Alzheimer's disease } \\
\text { diagnosed (years) }\end{array}$ & $0.8(1.0)$ & $0.9(1.2)$ & $0.8(1.0)$ \\
\hline \multicolumn{4}{|l|}{ Brain imaging findingsł } \\
\hline Territorial infarctions & $1(0.5)$ & $7(3)$ & $2(1)$ \\
\hline Lacunar infarctions & $17(8)$ & $10(5)$ & $16(7)$ \\
\hline White matter lesions & 0 & 0 & $2(1)$ \\
\hline Tumour & 0 & $1(0.5)$ & $1(0.5)$ \\
\hline
\end{tabular}

${ }^{*} \mathrm{n}=185$ for placebo, $\mathrm{n}=184$ for galantamine $24 \mathrm{mg}$, and $\mathrm{n}=179$ for galantamine $32 \mathrm{mg}$.

$\dagger 11$ item cognitive subscale.

łComputed tomography or magnetic resonance imaging findings in past 12 months.

\section{Primary efficacy variables}

At six months, patients who received galantamine had significantly better cognitive function than patients in the placebo group (difference in mean change in score from baseline on the 11 item cognitive subscale of the Alzheimer's disease assessment scale 3.1 (95\% confidence interval 1.7 to 4.5 ) for lower dose group and 4.1 (2.7 to 5.6) for higher dose group; $\mathrm{P}<0.001$ in both cases; fig 2, table 2). These differences were confirmed in the intention to treat analysis (table 2). The difference in mean change from baseline score increased progressively over time $(\mathrm{P}<0.0001$ for both doses). The improvement from baseline in cognitive function was significant at six months for the higher dose of galantamine $(\mathrm{P}<0.001)$ (table 2$)$. The fall in the placebo group was also significant $(\mathrm{P}<0.001)$. 


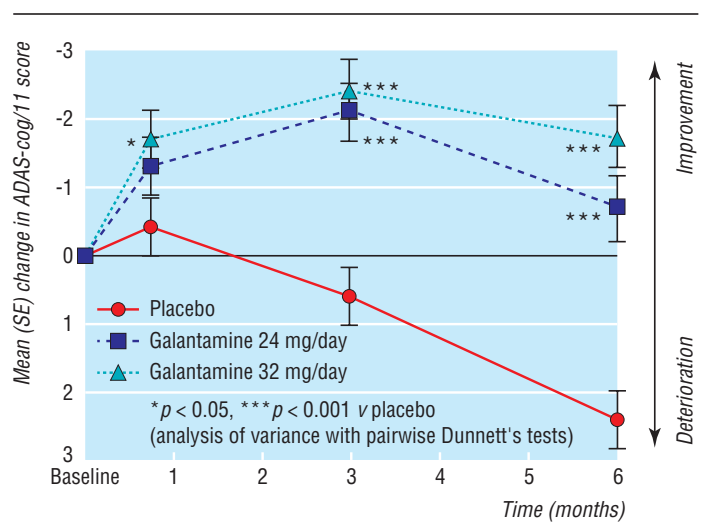

Fig 2 Mean (SE) change from baseline in score on 11 item cognitive subscale of Alzheimer's disease assessment scale over time, observed case analysis

Improvements in cognitive function from baseline in the galantamine groups were seen within one week of reaching a dose of $24 \mathrm{mg}$ daily (mean 1.3 (SE 0.36) points for lower dose and 1.7 (0.37) for higher doses; $\mathrm{P}<0.001$ in both cases). Galantamine produced a better outcome than placebo on the 11 item cognitive subscale of the Alzheimer's disease assessment scale regardless of the number of copies of the E4 apolipoprotein allele that a patient had (table 3 ).

An exploratory analysis showed that in patients with mild and moderate disease, both doses of galantamine were superior to placebo on the 11 item cognitive subscale of the Alzheimer's disease assessment scale (fig 3). The benefit was greatest for patients with moderately severe disease (baseline mini-mental state examination score $<18$ ), with a treatment differ- ence between placebo and the higher dose galantamine of 7.0 points at six months on the Alzheimer's disease assessment scale $(\mathrm{P}<0.001)$.

The effect of either dose of galantamine on the clinician's interview based impression of change plus caregiver input ratings was significantly better than that of placebo at six months in both the intention to treat and observed case analyses $(\mathrm{P}<0.05$ for all comparisons; table 2). More patients in the galantamine groups $(67-68 \%)$ improved or remained stable than in the placebo group (49\%).

\section{Secondary efficacy variables}

Galantamine produced a better outcome on the extended Alzheimer's disease assessment scale than placebo at six months; the treatment effect was 3.1 points for the lower dose and 4.0 points for the higher dose $(\mathrm{P}<0.001$, intention to treat and observed case analyses). More patients taking galantamine also improved on the 11 point scale than patients taking placebo (table 2).

After six months of treatment, the higher dose of galantamine produced a significantly better outcome on the disability assessment for dementia scale than placebo ( $\mathrm{P}<0.05$, intention to treat analysis) (table 2 ). The change from baseline in the total disability assessment for dementia score for the higher dose galantamine group was not significant, indicating that functional ability had been maintained (table 2). When both active treatment groups were combined for analysis, the difference between the placebo and galantamine groups in the mean change from baseline disability assessment score was 3.18 points $(\mathrm{P}<0.05)$.

\section{Safety}

At least 5\% more patients in the galantamine group than in the placebo group reported nausea, vomiting,

Table 2 Change from baseline in measures of efficacy at six months

\begin{tabular}{|c|c|c|c|c|c|c|c|c|c|c|}
\hline \multirow[b]{3}{*}{ Efficacy measure } & \multicolumn{5}{|c|}{ Intention to treat analysis } & \multicolumn{5}{|c|}{ Observed cases analysis } \\
\hline & \multirow[b]{2}{*}{ Placebo } & \multirow[b]{2}{*}{$\begin{array}{l}\text { Galantamine } \\
\quad 24 \mathrm{mg}\end{array}$} & \multirow[b]{2}{*}{$\begin{array}{l}\text { Galantamine } \\
\quad 32 \mathrm{mg}\end{array}$} & \multicolumn{2}{|c|}{ Treatment difference $(95 \% \mathrm{CI})^{*}$} & \multirow[b]{2}{*}{ Placebo } & \multirow[b]{2}{*}{$\begin{array}{l}\text { Galantamine } \\
24 \mathrm{mg}\end{array}$} & \multirow[b]{2}{*}{$\begin{array}{l}\text { Galantamine } \\
\quad 32 \mathrm{mg}\end{array}$} & \multicolumn{2}{|c|}{ Treatment difference $(95 \% \mathrm{CI})^{*}$} \\
\hline & & & & $\begin{array}{l}\text { Galantamine } \\
\quad 24 \mathrm{mg}\end{array}$ & $\begin{array}{l}\text { Galantamine } \\
32 \mathrm{mg}\end{array}$ & & & & $\begin{array}{l}\text { Galantamine } \\
\quad 24 \mathrm{mg}\end{array}$ & $\begin{array}{l}\text { Galantamine } \\
32 \mathrm{mg}\end{array}$ \\
\hline No of patients & 215 & 220 & 217 & & & 171 & 156 & 152 & & \\
\hline $\begin{array}{l}\text { Mean (SE) change } \\
\text { from baseline }\end{array}$ & $2.4(0.41)$ & $-0.5(0.38)$ & $-0.8(0.43)$ & $\begin{array}{c}2.9(1.6 \text { to } 4.1) \\
P<0.001\end{array}$ & $\begin{array}{c}3.1(1.9 \text { to } 4.4) \\
P<0.001\end{array}$ & $2.4(0.44)$ & $-0.7(0.48)$ & $-1.7(0.47)$ & $\begin{array}{c}3.1(1.7 \text { to } 4.5) \\
P<0.001\end{array}$ & $\begin{array}{c}4.1(2.7 \text { to } 5.6) \\
P<0.001\end{array}$ \\
\hline $\begin{array}{l}\text { No }(\%) \text { with } \geqslant 0 \\
\text { points improvement }\end{array}$ & $88(41)$ & $138(63)$ & $130(60)$ & $\begin{array}{l}21.5(12.0 \text { to } \\
31.0) P<0.001\end{array}$ & $\begin{array}{l}19.5(10.0 \text { to } \\
29.0) P<0.001\end{array}$ & $68(40)$ & $102(65)$ & $97(64)$ & $\begin{array}{l}25.5(15.0 \text { to } \\
36.0) P<0.001\end{array}$ & $\begin{array}{l}24.0(13.0 \text { to } \\
35.0) P<0.001\end{array}$ \\
\hline $\begin{array}{l}\text { No (\%) with } \geqslant 4 \\
\text { points improvement }\end{array}$ & $32(15)$ & $64(29)$ & $70(32)$ & $\begin{array}{c}14.0(6.0 \text { to } \\
22.0) P<0.001\end{array}$ & $\begin{array}{c}17.0(9.0 \text { to } \\
25.0) P<0.001\end{array}$ & $26(15)$ & $48(31)$ & $53(35)$ & $\begin{aligned} 16.0 & (7.0 \text { to } \\
25.0) & P<0.001\end{aligned}$ & $\begin{array}{c}19.5(10.0 \text { to } \\
29.0) P<0.001\end{array}$ \\
\hline \multicolumn{11}{|c|}{ Disability assessment for dementia scoreł } \\
\hline No of patients & 210 & 212 & 214 & & & 177 & 159 & 157 & & \\
\hline $\begin{array}{l}\text { Mean (SE) change } \\
\text { from baseline }\end{array}$ & $-6.0(1.08)$ & $-3.2(1.02)$ & $-2.5(1.07)$ & $\begin{array}{c}2.8(-0.6 \text { to } 6.1) \\
P=0.1\end{array}$ & $\begin{array}{c}3.4(0.1 \text { to } 6.7) \\
P<0.05\end{array}$ & $\begin{array}{c}-5.2 \\
(1.21) \\
\end{array}$ & $-2.7(1.17)$ & $-1.4(1.32)$ & $\begin{array}{c}2.5(-1.4 \text { to } 6.3) \\
P=0.3\end{array}$ & $\begin{array}{c}3.8(-0.1 \text { to } 7.7) \\
P=0.054\end{array}$ \\
\hline \multicolumn{11}{|c|}{ Clinician's interview based impression of change plus caregiver input } \\
\hline 1=Much improved & 0 & 0 & 0 & \multirow{7}{*}{$<0.05 \S$} & \multirow{7}{*}{$<0.001 \S$} & 0 & 0 & 0 & \multirow{7}{*}{$<0.01 \S$} & \multirow{7}{*}{$<0.001 \S$} \\
\hline $\begin{array}{l}\text { 2=Moderately } \\
\text { improved }\end{array}$ & $1(0.5)$ & $7(3)$ & $9(5)$ & & & $1(1)$ & $6(4)$ & $8(5)$ & & \\
\hline 3=Minimally improved & $32(16)$ & $29(14)$ & $39(20)$ & & & $29(17)$ & $27(17)$ & $35(23)$ & & \\
\hline 4=No change & $68(33)$ & $91(44)$ & $82(41)$ & & & $56(32)$ & $75(47)$ & $63(41)$ & & \\
\hline 5=Minimally worsened & $68(33)$ & $57(28)$ & $54(27)$ & & & $58(33)$ & $43(27)$ & $41(26)$ & & \\
\hline $\begin{array}{c}\text { 6=Moderately } \\
\text { worsened }\end{array}$ & $32(16)$ & $17(8)$ & $14(7)$ & & & $28(16)$ & $7(4)$ & $8(5)$ & & \\
\hline 7=Much worsened & $2(1)$ & $5(2)$ & $1(1)$ & & & $2(1)$ & $3(2)$ & 0 & & \\
\hline
\end{tabular}

*Difference from placebo.

†Negative change from baseline indicates improvement.

¥Negative change from baseline indicates deterioration.

$\S$ Van Elteren test was used to test for differences in the distribution of scores between placebo and galantamine groups. 
Table 3 Change from baseline in score on 11 item cognitive subscale of Alzheimer's disease assessement scale at six months according to apolipoprotein E genotype

\begin{tabular}{|c|c|c|c|c|c|}
\hline \multirow[b]{2}{*}{ No of copies of E4 allele } & \multicolumn{2}{|c|}{ Placebo group } & \multicolumn{2}{|c|}{ Galantamine groups } & \multirow[b]{2}{*}{$P$ value } \\
\hline & No of patients* & Mean (SE) change & No of patients* & Mean (SE) change & \\
\hline Two & 27 & $5.1(1.1)$ & 48 & $-1.5(0.7)$ & 0.0001 \\
\hline One & 67 & $1.9(0.6)$ & 138 & $-1.0(0.5)$ & 0.0008 \\
\hline None & 56 & $2.1(0.9)$ & 78 & $-1.7(0.7)$ & 0.0006 \\
\hline
\end{tabular}

*The low patient numbers reflect the fact that many patients did not give informed consent for apolipoprotein $\mathrm{E}$ genotyping.

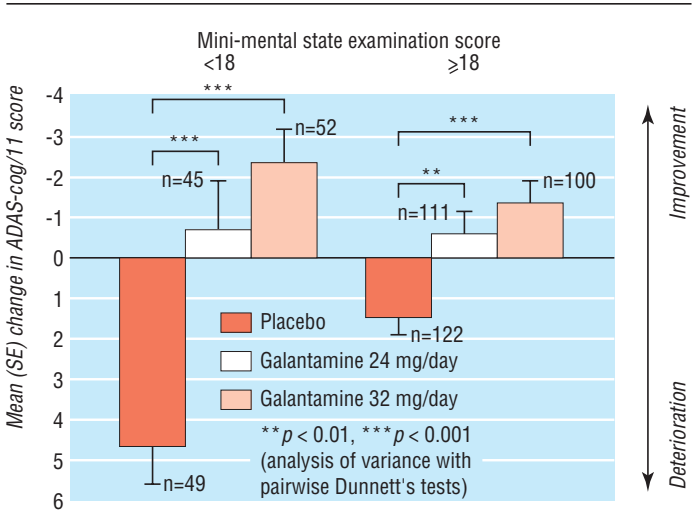

Fig 3 Mean (SE) change in 11 item cognitive subscale of the Alzheimer's disease assessment scale (ADAS-cog/11) scores at six months according to baseline score on mini-mental state examination, observed case analysis

diarrhoea, dizziness, headache, anorexia, and weight loss, with nausea being the most common adverse event (table 4). Nausea was rated as mild to moderate by most $(153 / 169)$ patients. About two thirds $(115 / 169)$ of the patients treated with galantamine who reported nausea had one episode, which usually started during the dose escalation period. The median duration was six days for the $24 \mathrm{mg}$ dose group and five days for the $32 \mathrm{mg}$ group. Most adverse events $(92 \%)$ were mild to moderate in severity, and the proportion of serious adverse events was similar in the three treatment groups (12-13\%).

Discontinuations due to adverse events were more common in patients who received galantamine $(18 \%$ $(79 / 438))$ than in patients in the placebo group $(9 \%$ (19/215), fig 1). More patients in the higher dose group (22\% (48/218)) discontinued treatment because of adverse events than in the lower dose group (14\% (31/ $220)$ ). The events most commonly associated with discontinuation from galantamine treatment were nausea $(10 \%(42 / 438))$ and vomiting (5\% (24/438)). About half of the patients who discontinued due to adverse events during galantamine treatment (43/79) stopped during the dose escalation phase. The monthly discontinuation rates during the subsequent five month maintenance phase for the galantamine groups $(2.1 \%$ and $2.4 \%$ ) were comparable to the discontinuation rate in the placebo group $(2.1 \%)$.

There were no consistent trends or clinically important differences between treatment groups in results of blood chemistry, haematology, urine analysis, pulse rate, blood pressure, or electrocardiographic measurements during the study. At six months, mean body weight had decreased by $1.4 \mathrm{~kg}$ in both galantamine treated groups compared with a slight increase $(0.2 \mathrm{~kg})$ in the placebo group $(\mathrm{P}<0.001$ for each comparison $v$ placebo).

\section{Discussion}

Our study shows that, compared with placebo, galantamine significantly improved cognition and global function in patients with mild to moderate Alzheimer's disease. These therapeutic effects were associated with significant benefits on patients' activities of daily living.

The clinical benefits of galantamine were seen with all three measures of cognitive function and in patients with both mild and moderate disease. The difference between the galantamine and placebo groups on the 11 item cognitive subscale of the Alzheimer's disease assessment scale was 7 points for patients with moderately severe disease. Although this was an exploratory analysis, it represents a large treatment effect. A global assessment, such as that provided by the clinician's interview based impressions of change plus caregiver input, is one way of measuring the clinical relevance of any improvements in cognitive function. ${ }^{24}$ This tool is based on the idea that if a drug's effect can be detected by a clinician during an interview with the patient and carer then this effect is likely to be clinically meaningful. We found a significant difference in the distribution of clinician interview scores between each galantamine group and placebo. Moreover, two thirds of patients who received galantamine were judged to have improved or remained stable at six months compared with half of those in the placebo group.

Galantamine had a significantly better effect on daily functioning than placebo. In addition, the change from baseline in disability assessment for dementia score at six months was not significant for the higher dose galantamine group, suggesting that activities of daily living had not deteriorated. As with all functional scales used in dementia studies, a clinically relevant treatment difference has not been defined for the disability assessment for dementia scale. Nevertheless, it is a validated, comprehensive measure of functional ability, ${ }^{21}$ and our results suggest that galantamine slows the progression of functional decline in patients with mild to moderate Alzheimer's disease. This outcome has been replicated in a similar study in the United

Table 4 Adverse events for which the difference between the galantamine and placebo groups was at least $5 \%$. Values are numbers (percentages) of patients

\begin{tabular}{lccc} 
Adverse event & Placebo group $(\mathbf{n}=\mathbf{2 1 5})$ & $\begin{array}{c}\text { Galantamine 24 } \mathbf{~ m g} \\
(\mathbf{n}=\mathbf{2 2 0})\end{array}$ & $\begin{array}{c}\text { Galantamine 32 } \mathbf{~ m g} \\
(\mathbf{n}=\mathbf{2 1 8})\end{array}$ \\
\hline Nausea & $26(12)$ & $82(37)$ & $87(40)$ \\
\hline Vomiting & $9(4)$ & $45(20)$ & $37(17)$ \\
\hline Diarrhoea & $16(7)$ & $16(7)$ & $29(13)$ \\
\hline Dizziness & $10(5)$ & $24(11)$ & $26(12)$ \\
\hline Headache & $7(3)$ & $21(10)$ & $25(11)$ \\
\hline Anorexia & 0 & $22(10)$ & $23(11)$ \\
\hline Weight loss & $1(0.5)$ & $17(8)$ & $11(5)$ \\
\hline Any adverse event & $165(77)$ & $182(83)$ & $194(89)$ \\
\hline
\end{tabular}


States. ${ }^{25}$ We would expect this effect to be clinically important because deterioration in functional ability often contributes to an increase in a patient's need for care. ${ }^{26}$

\section{Effects of other cholinesterase inhibitors}

The effects of traditional cholinesterase inhibitors on activities of daily living are unclear. ${ }^{6}$ Metrifonate was shown to have functional benefits in a six month study that used the disability assessment for dementia scale. ${ }^{27}$ Studies on donepezil have either not reported functional benefits ${ }^{28-30}$ or have shown benefit if basic activities of daily living (self care tasks such as dressing and personal hygiene) are removed from the analysis. ${ }^{31}$ Rivastigmine was also shown to have favourable effects on daily activities, ${ }^{32}{ }^{33}$ although the validity of these results has been questioned. ${ }^{6}$

The cognitive decline at six months in the placebo group in our study was at least as great as that found in placebo groups in other comparable studies. ${ }^{30-33}$ Similarly, the decline in activities of daily living in the placebo group was of a similar size to that reported in a placebo group in another study that used the same scale. ${ }^{27}$ These data suggest that galantamine's cognitive and functional benefits are unlikely to be due to the inclusion of patients with less severe disease. Also, for all measures we found a high degree of consistency between the results obtained in the intention to treat and observed case analyses.

As many as $70 \%$ of patients with Alzheimer's disease carry at least one copy of apolipoprotein E4. ${ }^{34}$ These patients seem to have a greater impairment of presynaptic cholinergic function than patients without the apolipoprotein $\mathrm{E} 4$ allele, which might be expected to reduce their response to treatment. However, galantamine significantly improved cognitive function, relative to placebo, regardless of patients' apolipoprotein $\mathrm{E}$ genotype. These findings contrast with results for tacrine ${ }^{8}$ but agree with a recent pooled analysis of metrifonate studies. ${ }^{35}$

\section{Side effects}

Galantamine was well tolerated by most patients. The completion rates for the two galantamine groups were comparable to those reported for other cholinesterase inhibitors. ${ }^{30-33}$ More adverse events were reported with the higher dose, and more patients who received the higher dose discontinued treatment as a result of adverse events. The most common adverse event in the galantamine groups was nausea, which has also been reported with other cholinesterase inhibitors. ${ }^{30}{ }^{31}{ }^{33}$ For most patients in our study, nausea was mild to moderate and lasted a median of five to six days.

The monthly rate of discontinuations due to adverse events with galantamine was comparable to the rate with placebo during the maintenance phase of the study, suggesting that the rapid, rigid dose escalation procedure may have contributed to patients discontinuing galantamine treatment. In a recent, five month, placebo controlled study of galantamine, in which the dose was escalated over eight weeks, the proportion of patients who discontinued galantamine 24 $\mathrm{mg}$ /day due to adverse events was low $(10 \%)$ and comparable to that in the placebo group $(7 \%) .{ }^{25}$ In clinical practice, patients' tolerance of galantamine might be improved by starting at a low dose and escalating the dose slowly. Apart from a small decrease in weight,
What is already known on this topic

Alzheimer's disease is characterised by a progressive decline in patients' cognitive function and ability to perform daily activities

Acetylcholinesterase inhibitors have been shown to improve cognitive function in patients with Alzheimer's disease

It is unclear whether changes in cognitive function, as measured on a psychometric scale, translate into clinically important outcomes for patients and their carers

\section{What this study adds}

Galantamine significantly improved cognitive function relative to placebo over six months

Treatment also slowed the progression of functional decline

The beneficial effect was evident in patients with and without the apolipoprotein $\mathrm{E} 4$ allele

galantamine had no clinically relevant effects on vital signs, laboratory tests, or electrocardiograms.

This study shows that galantamine is an effective and well tolerated treatment for Alzheimer's disease. Galantamine was effective regardless of patients' apolipoprotein E genotype. Comparator studies with traditional cholinesterase inhibitors are required to establish whether galantamine's concomitant effect on nicotinic receptors confers additional efficacy. Favourable effects on the progression of functional symptoms suggest that galantamine will produce clinically relevant benefits in patients with Alzheimer's disease.

The clinical investigators for the study were as follows: Canada: Addington D, Ancill R, Bergman H, Campbell B, Feldman H, Hutchings R, McCracken P, McKelvey R, Mohr E, Nair V, Naranjo C, Rabheru K, Rajput A, Robillard A, Van Reekum R, Veloso F.

Finland: Alhainen K, Erkinjuntti T, Hedman C, Jolma T, Koivisto K, Pirttilä T, Rinne J, Sulkava R, Tarvainen I

France: Auriacombe S, Benoit M, Borsotti J, Bouchacourt M, Boulliat J, Dourneau M, Feteanu D, Gras P, Guard O, Hourant C, Joyeux O, Lemarquis P, Rageot P, Rouch I, Verlhac B.

Germany: Benkert O, Frölich L, Hampel H, Heinze H, Horn R, Jauss M, Kessler C, Kornhuber J, Kurz A, Möller H, Rösler M, Schröder J, Uebelhack R, Wiltfang J.

Netherlands: Dautzenberg P, Eerenberg J, Groeneveld W, Kleyweg R, Pop P, Sanders E, Scheltens P, Siebenga E, van der Cammen T, Wiezer J, Wouters C.

Norway: Bjørnson L, Hoprekstad D, Nygaard H, Pettersen R, Radunovic Z, Sletvold O, Sparr S.

Sweden: Åhlin A, Andersson E, Andreasen N, Edman Å, Elofsson G, Eriksson L, Hansson G, Karlson I, Karlsson M, Kilander L, Klingén S, Mahnfeldt M, Marcusson J, Minthon L, Nagga K, Olofsson H, Passant U, Sjögren M, Syversen S, Wallin A, Werner-Bengtsson L.

United Kingdom: Bamrah J, Bullock R, Grimley Evans J, Katona C, Livingston G, O'Malley P, McKeith I, Somerville W, Thompson P, Vethanayagam S, Waite J, Wilcock G, Wilkinson D.

Contributors: GKW and SL participated in the design and execution of the study as well as analysis of data and writing the paper. EG participated in analysing and interpreting the data and writing the paper. GKW will act as the guarantor for the paper.

Funding: The study was supported by funding from Janssen Research Foundation, Beerse, Belgium. 
Competing interests: GKW's department receives research support from Shire Pharmaceuticals Group and Janssen Pharmaceutica, who have codeveloped galantamine. GKW has received consultancy fees from Shire Pharmaceuticals Group and Janssen Pharmaceutica.

1 Bartus RT, Dean RL, Beer B, Lippa AS. The cholinergic hypothesis of geriatric memory dysfunction. Science 1982;217:408-14.

2 Allen NHP, Burns A. The treatment of Alzheimer's disease.J Psychophar macol 1995;9:43-56.

3 Nordberg A, Svensson A-L. Cholinesterase inhibitors in the treatment of Alzheimer's disease: a comparison of tolerability and pharmacology. Drug Saf 1998;19:465-80.

4 Schneider LS. New therapeutic approaches to Alzheimer's disease. J Clin Psychiatry 1996;57(suppl 14):30-6.

5 Pryse-Phillips W. Do we have drugs for dementia? Arch Neurol 1999;56:735-7.

6 Bentham P, Gray R, Sellwood E, Raftery J. Effectiveness of rivastigmine in Alzheimer's disease. BMJ 1999;319:640.

7 MacGowan SH, Wilcock G, Scott M. Effect of gender and apolipoprotein E genotype on response to acetylcholinesterase therapy in Alzheimer's disease. Int J Geriatr Psychiatr 1998;13:625-30.

8 Farlow MR, Lahiri DK, Poirer J, Davignon J, Hui SL. Treatment outcome of tacrine therapy depends on apolipoprotein genotype and gender of the subjects with Alzheimer's disease. Neurology 1998;50:669-77.

9 Bores GM, Huger FP, Petko W, Mutlib AE, Camacho F, Rush DK, et al. Pharmacological evaluation of novel Alzheimer's disease therapeutics: acetylcholinesterase inhibitors related to galanthamine. J Pharmacol Exp Ther 1996;277:728-38.

10 Vasilenko ET, Tonkopii VD. Characteristics of galanthamine as reversible inhibitor of cholinesterase. Biokhimiia 1974;39:701-3.

11 Albuquerque EX, Alkondon M, Pereira EF, Castro NG, Schrattenholz A, Barbosa CT, et al. Properties of neuronal nicotinic acetylcholine receptors: pharmacological characterization and modulation of synaptic function. J Pharmacol Exp Ther 1997;280:1117-36.

12 Lawrence AD, Sahakian BJ. The cognitive psychopharmacology of Alzheimer's disease: focus on cholinergic systems. Neurochem Res 1998;23:787-94

13 Francis PT, Palmer AM, Snape M, Wilcock GK. The cholinergic hypothesis of Alzheimer's disease: a review of progress. I Neurol Neurosur Psychiatry 1999;66:137-47.

14 McKhann G, Drachman D, Folstein M, Katzman R, Price D, Stadlan EM. Clinical diagnosis of Alzheimer's disease: report of the NINCDS ADRDA work group under the auspices of Department of Health and Human Services Task Force on Alzheimer's disease. Neurology 1984;34:939-44.

15 Folstein MF, Folstein SE, McHugh PR. "Mini-mental state." A practical method for grading the cognitive state of patients for the clinician. J Psychiatr Res 1975:12:189-98.

16 Rosen WG, Mohs RC, Davis KL. A new rating scale for Alzheimer's disease. Am J Psychiatry 1984;141:1356-64.

17 Wendham PR, Price WH, Blundell G. Apolipoprotein E genotyping by one-stage PCR. Lancet 1991;337:1158-9.

18 Schneider LS, Olin JT, Doody RS, Clark CM, Morris JC, Reisberg B, et al. Validity and reliability of the Alzheimer's disease cooperative studyclinical global impression of change. Alzheimer Dis Assoc Disord 1997;11(suppl 2):22-32.
19 Mohs RC, Knopman D, Petersen RC, Ferris SH, Ernesto C, Grundman M, et al. Development of cognitive instruments for use in clinical trials of antidementia drugs: additions to the Alzheimer's disease assessment scale that broaden its scope. Alzheimer Dis Assoc Disord 1997;11(suppl 2):13-21.

20 Food and Drug Administration. Peripheral and central nervous system drug advisory committee meeting, July 7, 1989. Rockville, MD: Department of Health and Human Services, Public Heath Service, 1989:227.

21 Gelinas I, Gauthier L, McIntyre M, Gauthier S. Development of a functional measure for persons with Alzheimer's disease: the disability assessment for dementia. Am J Occup Ther 1999;53:471-81.

22 Knapp MJ, Knopman DS, Solomon PR, Pendlebury WW, Davis CS, Gracon SI. A 30-week randomized controlled trial of high-dose tacrine in patients with Alzheimer's disease. JAMA 1994;271:985-91.

23 Van Elteren PH. On the combination of independent two sample tests of Wilcoxon. Bull Inst Intern Statist 1960;37:351-61.

24 Committee for Proprietary Medicinal Products. Note for guidance on medicinal products in the treatment of Alzheimer's disease. London: European Agency for the Evaluation of Medicinal Products, 1997.

25 Tariot P, Solomon P, Morris J, Kershaw P, Lilienfeld S, Parys W, et al. A 5 -month, randomized, placebo-controlled study of galantamine in $\mathrm{AD}$ Neurology 2000;54:2269-76.

26 Canadian Study of Health and Aging. Patterns of caring for people with dementia in Canada. Can J Aging 1994;13:470-87.

27 Dubois B, McKeith I, Orgogozo J-M, Collins O, Meuliens D, MALT Study Group. A multicentre, randomized, double-blind, placebo-controlled study to evaluate the efficacy, tolerability and safety of two doses of metrifonate in patients with mild-to-moderate Alzheimer's disease: the MALT study. Int J Geriatr Psychiatry 1999;14:973-82.

28 Rogers SL, Friedhoff LT, Donepezil Study Group. The efficacy and safety of donepezil in patients with Alzheimer's disease: results of US multicentre, randomized, double-blind, placebo-controlled trial. Dementia 1996;7:293-303.

29 Rogers SL, Doody RS, Mohs RC, Friedhoff LT, Donepezil Study Group. Donepezil improves cognition and global function in Alzheimer disease. Arch Intern Med 1998;158:1021-31.

30 Rogers SL, Farlow MR, Doody RS, Mohs R, Friedhoff LT, Donepezil Study Group. A 24-week, double-blind, placebo-controlled trial of donepezil in patients with Alzheimer's disease. Neurology 1998;50:136-45.

31 Burns A, Rossor M, Hecker J, Gauthier S, Petit H, Möller H-J, et al. The effects of donepezil in Alzheimer's disease-results from a multinational trial. Dement Geriatr Cogn Disord 1999;10:237-44.

32 Corey-Bloom J, Anand R, Veach J, ENA 713 B352 Study Group. A randomized trial evaluating the efficacy and safety of ENA 713 (rivastigmine tartrate), a new acetylcholinesterase inhibitor, in patients with mild to moderately severe Alzheimer's disease. Int J Geriatr Psychopharmaco 1998;1:55-65.

33 Rösler M, Anand R, Cicin-Sain A, Gauthier S, Agid Y, Dal-Bianco P, et al Efficacy and safety of rivastigmine in patients with Alzheimer's disease: international randomised controlled trial. BMJ 1999:318:633-8.

34 Higgins GA, Large CH, Rupnik HT, Barnes JC. Apolipoprotein E and Alzheimer's disease: a review of recent studies. Pharmacol Biochem Behav 1997;56:675-85.

35 Farlow MR, Cyrus PA, Nadel A, Lahiri DK, Brashear A, Gulanski B. Metrifonate treatment of AD: influence of APOE genotype. Neurology 1999;53:2010-6.

(Accepted 10 August 2000)- 